\title{
Numerical Investigation of Tool Parameters Influence on the Interlock Forming During Flat Clinching Process
}

\section{Zhiyong Wang}

Shandong University of Science and Technology https://orcid.org/0000-0003-1530-3103

Shanling Han ( $\square$ Hanshanling@sdust.edu.cn)

Shandong University of Science and Technology https://orcid.org/0000-0001-8108-6843

Zhiyong Li

Shandong University of Science and Technology

Yong Li

Shandong University of Science and Technology

\section{Research Article}

Keywords: Flat clinching, Aluminum alloy, Tool parameter, Interlock forming

Posted Date: October 27th, 2021

DOI: https://doi.org/10.21203/rs.3.rs-949396/v1

License: (c) (i) This work is licensed under a Creative Commons Attribution 4.0 International License. Read Full License 


\section{Abstract}

Tool parameters play a vital role in the mechanical interlock formation during the flat clinching process, to understand the influence of tool parameters on the interlock formation, the finite element software DEFORM-2D was used to build the numerical model of the flat clinching process, and the numerical model was verified by the experiment. The influences of the punch radius, punch fillet radius, and blank holder radius on the interlock formation of the clinched joint were investigated using the numerical model. Then, the relationship between the punch radius and blank holder radius was studied. The results showed that the interlock gradually increases with the increase of the blank holder radius, after that, the interlock begins to decrease. To maximize the interlock, the punch radius and the blank holder radius should be increased simultaneously. It can be concluded that the blank holder radius and the punch radius should keep in a linear relationship when designing the geometric dimensions of the flat clinch tools, which can promote the application of flat clinching process in car body manufacturing.

\section{Introduction}

To increase fuel economy and reduce exhaust gas emissions, lightweight materials have been a strategy for building vehicle body structures, suitable joining techniques are required to create such structures[1, 2]. Some mechanical joining processes, such as mechanical clinching, have been developed for joining these hard-to-weld lightweight materials[3]. In the clinching process, two or more workpieces can interlock together only by local plastic deformation without additional elements[4]. The mechanical clinching process is used to join many materials, such as steels, aluminum alloys, magnesium alloys, titanium alloys, and carbon fiber reinforced plastics (CFRP) $[5,6,7]$. Mechanical clinching has become a viable option for joining similar or dissimilar lightweight materials.

In mechanical clinching process, two or more overlapping metal sheets are joined by local plastic deformation, so that a clinched joint with a die-side protrusion can be obtained. Due to this protrusion, conventional clinching technology cannot be used for visible and functional surfaces[8]. To solve this problem, Wen et al.[9] proposed a reshaping method in which a pair of contoured tools is used to compress the clinched joint. Chen et al.[10,11] used a pair of flat dies to decrease the protruding height of conventional clinched joint, enlarges the neck thickness and interlock of the joint. Chen et al.[12] divided the reshaping process into two steps, and used a special rivet in the second step to produce a reshaped joint with a rivet. Lambiase and Ko[13] investigated the effectiveness of two-steps clinching for joining aluminum and CFRP, the reshaping process could improve the strength of the joints but result in damage to CFRP sheet. The reshaping method with(or without) a rivet increases the joint strength and reduce the protrusion, but the process is complex and time-consuming, for sheets need to be turned and positioned during the reshaping process[14]. Wen et al.[15] investigated the flat hole clinching process to form a joint with a flat surface, it needs a hole to be pre-punched before joining, which reduces work efficiency. All the above reshaping methods suffer from increased cycle time due to the additional step. 
To solve this problem, flat clinching technology was developed at Chemnitz University of Technology, flat clinching technique is a one-step method that using a punch, blank holder, and flat anvil, a one-sided planar joint can be produced in the process. The flat-clinched joint is formed by the sheet material flows upwards and radially in the control of the blank holder[14]. The geometrical of punch and blank holder are the critical factors affecting the quality of the flat-clinched joint. Many investigations have been carried out to study the effect of different geometries and structures of tools on the mechanical strength of the flat-clinched joint to obtain the best joint quality. Lüder et al.[16] investigated the influence of moisture content in wood on the strength of the flat clinched joint. Han et al.[17] used the orthogonal experimental design simulation method to optimize the geometrical parameters, results show that the punch fillet radius and the blank holder radius have a significant impact on the flat-clinched joint. However, the punch diameter was not taken into account, and the parameter interactions were assumed to be negligible in her study. Chen et al.[18] investigated the effect of punch diameter and holder force on materials deforming behavior and quality of the flat-clinched joint, the results showed that an increase in punch diameter could improve the neck thickness and interlock, and a higher holder force is required for restricting the material flow. The changes in the radius of the blank holder were not taken into account in the study. Atia et al.[19] studied the joining process of AA7075 aluminum alloy in different temper conditions by flat clinching, they investigated the effect of blank holder parameters and forming force on the interlock shapes, found that the blank holder groove was effective in enhancing the interlock formation, a modest decrease in groove blank holder depth improved interlock formation, a blank holder groove diameter greater than $150 \%$ of the punch diameter and groove depth greater than $20 \%$ of sheet thickness are recommended to the flat clinch joining process. In another work, Atia et al.[20] investigated the influence of the blank holder parameters on material flow and the geometric structure of the die-less clinched joints by a numerical method, they indicated that increase the grove diameter or decrease the blank holder depth enables the interlock depth to increase. Furthermore, Atia[21] jointed high strength AA7075 aluminum sheets by hot die-less clinching with an electrical resistance heating method in which the local region was heated. Chen et al.[22] investigated the flat-clinching process for joining three-layer sheets on thin-walled structures. Gerstmann and Awiszus[8] developed a flat-clinch-bonding technique as a combination of flat clinching and adhesive bonding, after gluing, metal sheets can be mechanically connected by flat-clinching, this ensures the assembly strength and shortens the processing time. However, the relationship between the punch radius and blank holder radius in the flat-clinching process was not studied in their studies.

The present study aims to elaborate on the influence of punch radius, punch fillet radius, and blank holder radius on the mechanical interlock forming of the flat-clinching joint, and the interrelationships among these tool parameters. The finite element model was built using the DEFORM-2D software, and Al5052 was chosen as the material of the two sheets. This model is then used to simulate the flat-clinch joining process and assess the effect of the tool parameters on the mechanical interlock.

\section{Materials And Methods}




\subsection{Materials}

The sheet used in this finite element simulation is made of Al5052-0 aluminum alloy, the mechanical properties of Al5052-O sheet is shown in Table 1, the constitutive behavior of Al5052-0 aluminum alloy is described by the true stress-strain curve, as shown in Equation (1)[23]:

Table 1

Mechanical properties of Al5052-0 sheet[23]

\begin{tabular}{|ll|}
\hline Properties & Value \\
\hline Density $\left(\mathrm{kg} / \mathrm{m}^{3}\right)$ & 2700 \\
\hline Yield strength $(\mathrm{MPa})$ & 116.64 \\
\hline Tensile strength $(\mathrm{MPa})$ & 209.37 \\
\hline Elasticity modulus $(\mathrm{GPa})$ & 72 \\
\hline Poisson's ratio & 0.3 \\
\hline
\end{tabular}

$\sigma=377.23 \varepsilon^{025}$

(1)

where $\sigma$ is the true stress and $\varepsilon$ is the true strain. The Voce hardening model was implemented to fit the stress-strain curve for describing the material behavior of Al5052. Plastic material models were used to assume the upper sheet and lower sheet, while the punch, blank holder, and flat anvil were considered as rigid bodies.

\subsection{Mechanism of flat-clinching}

Flat-clinching is a one-step joining method by forming process, in which a punch, blank holder, and flat anvil are used, as shown in Fig. 1. In the flat-clinching process, the two sheets are placed upon a flat anvil, the blank holder moves down to press the sheets down. Afterward, the punch moves downward for stamping the sheets. With the restriction of the blank holder, the material would flow upward rather than flow radially, the upper sheet material flow into the gap between the punch and blank holder, meanwhile, the lower sheet material also flows upward. Finally, the material below the punch flow radially, a mechanical interlock is formed between the two sheets.

The main geometric parameters that affect the mechanical properties of the flat-clinched joint are shown in Fig. 2, including the interlock length $\left(t_{s}\right)$, neck thickness $\left(t_{n}\right)$, and bottom thickness $(X)$. Due to the smaller interlock, the shear strength of the flat-clinched joints is much higher than its tensile strength, the lack of tensile strength is the main reason for flat-clinched joint failures[24]. Therefore, the mechanical interlock is often used to assess the property of the flat-clinched joint in the following discussion. 
Experiments have often been used to adjust tool geometry and process parameters in the clinching process, which take a lot of time and quite expensive. To overcome this problem, the finite element method is frequently used to investigate the joining process, mechanical properties, and failure mechanisms of the clinched joints[25]. Wang et al.[26] carried out the investigations and modeling for clinch joining process design using finite element simulation. Tenorio et al.[27] studied the effect of tool geometries and process parameters on the strength of clinched joints using the finite element method.

The formation of mechanical interlock mainly depends on the configuration of the tools[28], to study the influence of the tools geometrical parameters on the property of the flat-clinched joint, as shown in Fig. 3 , different punch radius $\left(r_{p}\right)$ of $2.55,2.75,2.95$, and $3.20 \mathrm{~mm}$ are adopted in the finite element simulation, and punch fillet radius $\left(r_{0}\right)$ is set to $0.1,0.2$ and $0.3 \mathrm{~mm}$, and blank holder radius $\left(r_{h}\right)$ is set to $3.80,4.20$, $4.50,4.80,5.00,5.50 \mathrm{~mm}$, etc.

The purpose of this simulation is to investigate the effect of punch and blank holder geometrical parameters on the flat-clinched joint. To reduce computational resource usage, the simulations of flatclinching were carried out using an axi-symmetric model. The simulations were carried out using the finite element software DEFORM-2D. Quadrilateral elements were used to mesh the sheets, to prevent the mesh distortion, the automatic remeshing method was used in the finite element simulation. The shear friction model was chosen to model the friction conditions at the contact surfaces. The friction coefficients between the sheets and tools were set as 0.15 [29], and the friction coefficient between the upper sheet and the lower sheet was set as 0.3[9]. The blank holder and the flat anvil are fixed, the thickness of the upper sheet and lower sheet is $2 \mathrm{~mm}$, bottom thickness $(X)$ was always fixed in $20 \%$ of the total thickness of two sheets, and the punch moves downwards with a speed of $0.5 \mathrm{~mm} / \mathrm{s}$, and the time increment is $0.1 \mathrm{~s}$. To avoid mesh distortion, automatic remeshing was performed every ten steps in the finite element simulation.

\subsection{Experiment}

Joining dies manufactured by molded steel is shown in Fig. 4, the punch is installed on the upper die, the blank holder is installed on the sliding die, and the anvil is installed on the lower die, the springs are sleeved on the slide column between the upper die and the sliding die. Thus, with the movement of the punch, a holder force can be generated on the blank holder. The flat-clinching experiment was carried out on an HYDLIC press machine (HYDLIC Company, Dongguan city, China). During the joining process, the velocity of the punch is $0.5 \mathrm{~mm} / \mathrm{s}$, and the stroke of the punch is $3.6 \mathrm{~mm}$.

\section{Results And Discussion}

\subsection{FE model validation}

Before using the numerical model to carry out the finite element simulation, a model validation was carried out to verify the accuracy of the numerical model. Thus, experimental data were used to compare with the numerical results in terms of the neck thickness and interlocking length, the cross-sections of the 
flat-clinched joint obtained from experiments and numerical model are shown in Fig. 5. The numerical results agreed well with the experimental data in respect of the neck thickness and interlocking length of the flat-clinched joint. The cross-section of the numerical model is similar to that of the experiment, which proves that the numerical model can be used to predict the outcome of a flat-clinching process with accuracy.

\subsection{Material flow}

Material flow during the flat-clinching process is shown in Fig. 6. The flat-clinching process can be divided into four stages. Within stage 1 , with the downwards movement of the punch, the sheet material under the punch flow in the same direction, while the material around the punch region flows in the radial direction, as shown in Fig. 6(a).

In stage 2, with the further punch movement, it becomes increasingly difficult for the upper sheet material to flow in the radial direction due to the limitation of the blank holder, then the upper sheet material flow in the axial direction to the gap between the punch and blank holder, the lower sheet flow in both the radial and axial direction shows in Fig. 6(b). Stage 3, the upper sheet material flow in the axial direction gradually becomes difficult, while the upper sheet material outside the punch fillet region exerts higher pressure on the interface between it and the lower sheet material, then the upper sheet material flow in the radial direction increases significantly, and the lower sheet material flow in the axial direction increases significantly shows in Fig. 6(c). Stage 4, with punch moves downwards, upper sheet material around the punch fillet flows in the radial direction continuously, and the lower sheet material flows in the axial direction, which results in the formation of the mechanical interlocking shows in Fig. 6(d).

\subsection{Influence of blank holder radius on the joint}

The blank holder groove is a key factor in controlling the material flow to form the mechanical interlock between the two sheets[19], different blank holder radii were selected to study its effect on the interlock of the flat-clinched joint at $2.95 \mathrm{~mm}$ punch radius and $0.1 \mathrm{~mm}$ punch fillet radius, the final flat-clinched joint shapes are shown in Fig. 7.

In these four joint shapes, the interlocks (or S-shapes) were formed at different blank holder radii, and the lower part of the S-shapes are almost the same, but the upper part of the $\mathrm{S}$-shapes are quite different due to the difference of the blank holder radius. As shown, the interlock formed at $4.2 \mathrm{~mm}$ and $5.5 \mathrm{~mm}$ blank holder radius are smaller than that formed at $4.5 \mathrm{~mm}$ and $5.0 \mathrm{~mm}$ blank holder radius, blank holder radius mainly affects the forming of the upper part of the S-shape by controlling the material flow, Fig. 7 indicates that the material of the lower sheet flows in the radial direction are increased at the blank holder radius of $4.20 \mathrm{~mm}$ and $5.50 \mathrm{~mm}$. Too large or too small blank holder radius is not conducive to the increase of interlock length. Therefore, a moderate blank holder radius is required for a punch diameter, it should not be too large or too small.

For explanation, the sheet material flow velocity at different blank holder radii was analyzed, the material flow at punch stroke of $3.0 \mathrm{~mm}$ was chosen, as shown in Fig. 8. It indicates that the lower sheet material 
flow mainly in the axis direction for the blank holder radius of $4.50 \mathrm{~mm}$ and $5.00 \mathrm{~mm}$, while the material flow increased in the radial direction at the blank holder radius of $4.20 \mathrm{~mm}$ and $5.50 \mathrm{~mm}$, which result in the smaller upper parts of the S-shape. Therefore, the increase of lower sheet material flow in the axis direction can give rise to the improvement of the interlock.

\subsection{Influence of punch radius and punch fillet radius on the joint}

The interlock shapes from different punch radii are shown in Fig. 9, when the blank holder radius $\left(r_{b}=5.00 \mathrm{~mm}\right)$ and punch fillet radius $\left(r_{0}=0.1\right)$ are constants, with the increase of punch radius, more materials under the punch will be pushed around the punch, which leads to an increase in the interlocks[18]. Meanwhile, the whole S-shape moves along the radial direction and axis direction.

However, when the blank holder radius is reduced to $4.50 \mathrm{~mm}$, the increase of punch radius has no obvious effect on the improvement of interlock, as shown in Fig. 10. Furthermore, when the blank holder radius decreased to $4.20 \mathrm{~mm}$, the interlock decreases with the increase of the punch radius. It can be inferred that the influence of the punch radius on interlock is also affected by the blank holder radius, only when the blank holder radius is appropriate, the increased punch radius can improve the mechanical interlock.

The final shapes of the flat-clinched joints at different punch fillet radii at $2.95 \mathrm{~mm}$ punch radius and $5.00 \mathrm{~mm}$ blank holder radius are shown in Fig. 11(a), The smaller the punch fillet radius, the lower is the protrusion height, which indicates that the smaller punch fillet radius decreases the material flow in the axial direction. By contrast, a smaller punch fillet radius can give a rise to the increase of the material flow in the radius direction, increasing the lower part of the S-shape, as shown in Fig. 11(b). The smaller the punch fillet radius is, the greater the interlock is, as shown in Fig. 12, with the punch fillet radius increased from 0.3 to 0.2 and 0.1 , the interlock volume increased by $33.8 \%$ and $56.4 \%$, respectively. Therefore, it can be inferred that a small punch fillet radius has an important effect on the increase of joint interlock by promoting the material flow in the radial direction from the axial direction.

The velocity of the materials passing through the fixed point P1(shows in Fig. 11(a)) is obtained by point tracking, as shown in Fig. 13, a smaller punch fillet radius reduces the material flow in the axis direction during the flat-clinching process, that's why the protrusion height is lower when the punch fillet radius is smaller.

The movement of the moving point P2 (see Fig. 14) in the flat-clinching process was traced, P2 flow upwards along the surface of the punch. Also, the flow velocity of the moving point P2 at different punch fillet radii was achieved by point tracking, as shown in Fig. 15.

The smaller the punch fillet radius, the lower the flow velocity of the moving point $\mathrm{P} 2$, meanwhile, the smaller the punch fillet radius is, the more violent the flow velocity curve is, it is inferred that a decrease in punch fillet radius impeded the material flow. 


\subsection{The effect of punch radius, punch fillet radius, and blank holder radius on the interlock}

Figure 16 shows the effect of the punch fillet radius and blank holder radius on the interlock at different punch radii. Figure 16(a-d) shows the effect of the blank holder radius on interlock at different punch fillet radii and $3.20 \mathrm{~mm}$ punch radius, note that with the decrease of punch fillet radius, the interlock increases, which also can be seen in all of the other images in Fig. 11. It can be inferred that a small punch fillet radius can facilitate the formation of mechanical interlocks regardless of the punch radius and blank holder radius.

With the increase of the blank holder radius, the interlock length also gradually increases, but, after the interlock length reaches its maximum, it begins to decrease, as seen in Fig. 16.

The effect of blank holder radius and punch radius on the interlock of the flat-clinched joint at $0.1 \mathrm{~mm}$ punch fillet radius was selected, as shown in Fig. 17. This trend is also true for punch fillet radii of 0.2 and 0.3. To maximize the interlock, the punch radius and the blank holder radius should be increased simultaneously, meanwhile, there is a certain correlation between these two parameters, as shown in Fig. 18. It can be seen that the correlation between these two parameters is approximately linear, so a linear fitting was carried out, and the following formula was achieved.

$$
r_{p}=1.215 * r_{h}+1127
$$

It can be inferred that the blank holder radius and the punch radius should keep in this linear relationship when designing the geometric dimensions of the tool.

\section{Conclusion}

In the present work, the flat-clinching process was investigated using the finite element method, the effect of tool parameters such as punch radius, punch fillet radius, and blank holder radius on the material flow and the interlock of the flat-clinched joint were investigated, then, the interaction between parameters was investigated, the main conclusions of the present work can be drawn as follows:

1. The formation of the mechanical interlock requires the collaborative flow of upper sheet material and lower sheet material, the interlock can be improved by facilitating the upper sheet material flow in the radial direction and the lower sheet material flow in the axial direction.

2. With the increase of the blank holder radius, the interlock length also gradually increases, but, after the interlock length reaches its maximum, the interlock length begins to decrease.

3. The smaller the punch fillet radius is, the more it impedes the upper sheet material flows around the punch, a small punch fillet radius has an important effect on the increase of joint interlock by promoting the material flow in the radial direction from the axial direction. 
4. The influence of the punch radius on interlock is also affected by the blank holder radius, only when the blank holder radius is appropriate, the increased punch radius can improve the interlock. To maximize the interlock, a moderate blank holder radius is required for a punch diameter, and the correlation between these two parameters is approximately linear.

\section{Declarations}

\section{Availability of data and materials}

All data generated or analyzed during this study are included in the present article.

\section{Funding}

The authors acknowledge funding by the National Nature Science Foundation of Shandong Province of China (Grant No. ZR2018MEE024), A Project of Shandong Province Higher Educational Science and Technology Program (Grant No. J17KA018).

\section{Author information}

\section{Affiliations}

College of Mechanical and Electronic Engineering, Shandong University of Science and Technology, Qingdao, 266590, China;

Zhiyong Wang, Shanling Han, Zhiyong Li \& Yong Li

College of Mechatronics Engineering, Binzhou University, Binzhou, 256600, China

Zhiyong Wang

\section{Contributions}

Not applicable.

\section{Corresponding author}

Correspondence to Shanling Han

\section{Ethics declarations}

\section{Ethical approval}

This research did not involve human participants or animals; thus, an ethics approval is not necessary. 
Not applicable.

\section{Consent to publish}

Not applicable.

\section{Competing interests}

The author declares no competing interests.

\section{References}

1. Dilthey U, Stein $L$ (2006) Multimaterial car body design: challenge for welding and joining. Sci Technol Weld Joining 11(2):135-142. doi:10.1179/174329306x85967

2. Meschut G, Hahn O, Janzen $V$ et al (2014) Innovative joining technologies for multi-material structures. Weld World 58(1):65-75. doi:10.1007/s40194-013-0098-3

3. Çam G, İpekoğlu G (2017) Recent developments in joining of aluminum alloys. Int J Adv Manuf Technol 91(5):1851-1866. doi:10.1007/s00170-016-9861-0

4. Salamati M, Soltanpour M, Fazli A et al (2019) Processing and tooling considerations in joining by forming technologies; part A-mechanical joining. Int J Adv Manuf Technol 101(1):261-315. doi:10.1007/s00170-018-2823-y

5. Galińska A, Galinski C (2020) Mechanical joining of fibre reinforced polymer composites to metals-a review. Part II: riveting, clinching, non-adhesive form-locked joints, pin and loop joining. Polymers 12(8):1681. doi:10.3390/polym12081681

6. Wang J, Yu Y, Fu C et al (2020) Experimental investigation of clinching CFRP/aluminum alloy sheet with prepreg sandwich structure. J Mater Process Technol 277:116422. doi:10.1016/j.jmatprotec.2019.116422

7. He X (2017) Clinching for sheet materials. Sci Technol Adv Mater 18(1):381-405. doi:10.1080/14686996.2017.1320930

8. Gerstmann T, Awiszus B (2020) Hybrid joining: Numerical process development of flat-clinchbonding. J Mater Process Technol 277:116421. doi:10.1016/j.jmatprotec.2019.116421

9. Wen $\mathrm{T}$, Wang $\mathrm{H}$, Yang $\mathrm{C}$ et al (2014) On a reshaping method of clinched joints to reduce the protrusion height. Int J Adv Manuf Technol 71(9):1709-1715. doi:10.1007/s00170-014-5612-2

10. Chen C, Zhao S, Cui M et al (2016) An experimental study on the compressing process for joining Al6061 sheets. Thin-Walled Struct 108:56-63. doi:10.1016/j.tws.2016.08.007

11. Chen C, Zhao S, Han X et al (2017) Experimental investigation of the mechanical reshaping process for joining aluminum alloy sheets with different thicknesses. J Manuf Processes 26(4):105-112. doi:10.1016/j.jmapro.2017.01.015

12. Chen C, Zhao S, Cui M et al (2016) Mechanical properties of the two-steps clinched joint with a clinch-rivet. J Mater Process Technol 237:361-370. doi:10.1016/j.jmatprotec.2016.06.024 
13. Lambiase F, Ko D-C (2017) Two-steps clinching of aluminum and Carbon Fiber Reinforced Polymer sheets. Compos Struct 164:180-188. doi:10.1016/j.compstruct.2016.12.072

14. Peng $\mathrm{H}$, Chen $\mathrm{C}$, Zhang $\mathrm{H}$ et al (2020) Recent development of improved clinching process. Int J Adv Manuf Technol 110(11):1-31. doi:10.1007/s00170-020-05978-4

15. Wen T, Huang Q, Liu Q et al (2016) Joining different metallic sheets without protrusion by flat hole clinching process. Int J Adv Manuf Technol 85(1):217-225. doi:10.1007/s00170-015-7936-y

16. Lüder S, H?Rtel S, Binotsch C et al (2014) Influence of the moisture content on flat-clinch connection of wood materials and aluminium. J Mater Process Technol 214(10):2069-2074.

doi:10.1016/j.jmatprotec.2014.01.010

17. Han X, Zhao S, Chen $C$ et al (2017) Optimization of geometrical design of clinching tools in flatclinching. Proc Inst Mech Eng Part C: J Mech Eng Sci 231(21):4012-4021. doi:10.1177/0954406216660335

18. Chen C, Zhao S, Han X et al (2017) Investigation of flat clinching process combined with material forming technology for aluminum alloy. Materials 10(12):1433. doi:10.3390/ma10121433

19. Sabra Atia MK, Jain MK (2017) Die-less clinching process and joint strength of AA7075 aluminum joints. Thin-Walled Struct 120:421-431. doi:10.1016/j.tws.2017.06.021

20. Atia MKS, Jain MK (2018) Finite element analysis of material flow in die-less clinching process and joint strength assessment. Thin-Walled Struct 127:500-515. doi:10.1016/j.tws.2018.03.001

21. Atia MKS, Jain MK (2020) A novel approach to hot die-less clinching process for high strength AA7075-T6 sheets. Proc Inst Mech Eng Part C: J Mech Eng Sci 234(19):17.

doi:10.1177/0954406220917406

22. Chen $\mathrm{C}$, Zhang $\mathrm{H}$, Xu Y et al (2020) Investigation of the flat-clinching process for joining three-layer sheets on thin-walled structures. Thin-Walled Struct 157:107034. doi:10.1016/j.tws.2020.107034

23. Feng F, Li JJ, Yuan P et al (2018) Application of a GTN Damage Model Predicting the Fracture of 5052-0 Aluminum Alloy High-Speed Electromagnetic Impaction. Metals 8(10):761-780. doi:10.3390/met8100761

24. Gerstmann T, Awiszus B (2014) Recent developments in flat-clinching. Comput Mater Sci 81:39-44. doi:10.1016/j.commatsci.2013.07.013

25. Flodr J, Lehner P, Krejsa MJS (2020) Experimental and numerical evaluation of clinch connections of thin-walled building structures. Sustainability 12(14):5691. doi:10.3390/su12145691

26. Wang X, Li X, Shen Z et al (2018) Finite element simulation on investigations, modeling, and multiobjective optimization for clinch joining process design accounting for process parameters and design constraints. Int J Adv Manuf Technol 96(1):1-21. doi:10.1007/s00170-018-1708-4

27. Tenorio MB, Lajarin SF, Gipiela ML et al (2019) The influence of tool geometry and process parameters on joined sheets by clinching. J Braz Soc Mech Sci Eng 41(2):67. doi:10.1007/s40430018-1539-0 
28. Barimani-Varandi A, Aghchai AJJM (2020) Electrically-assisted mechanical clinching of AA6061-T6 aluminum to galvanized DP590 steel: effect of geometrical features on material flow and mechanical strength. Mechanics Industry 21(5):529. doi:10.1051/meca/2020072

29. Lambiase F, Di llio A (2013) Finite element analysis of material flow in mechanical clinching with extensible dies. J Mater Eng Perform 22(6):1629-1636. doi:10.1007/s11665-012-0451-5

\section{Figures}

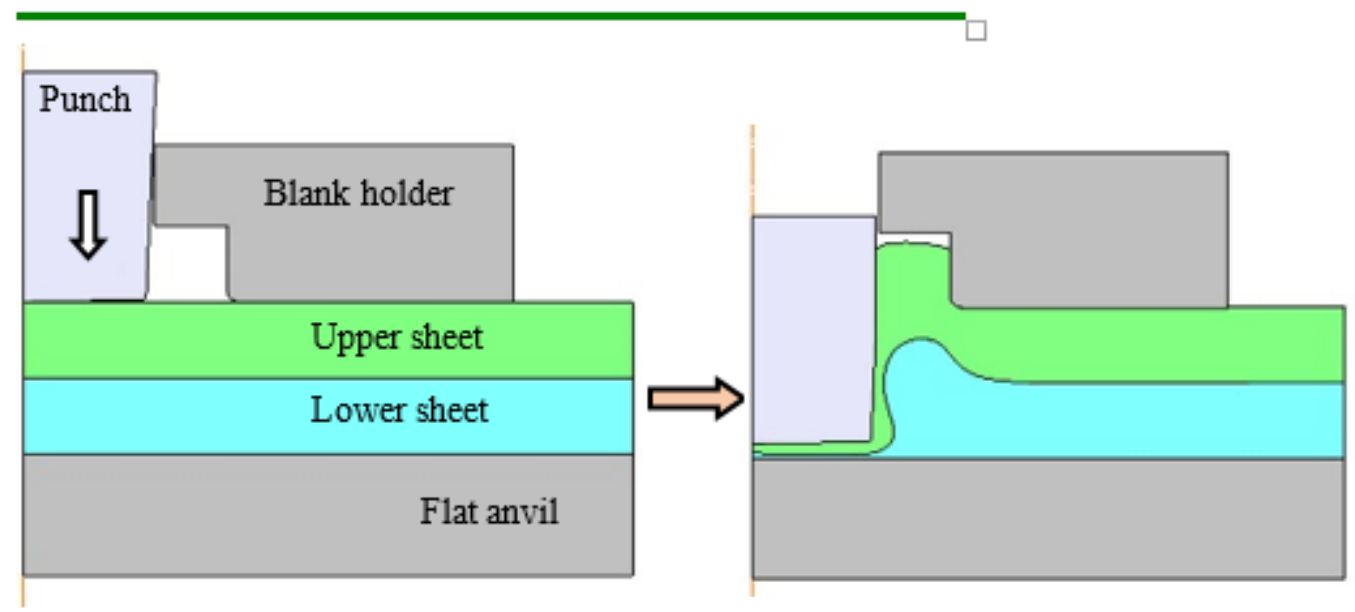

\section{Figure 1}

Flat-clinching process.

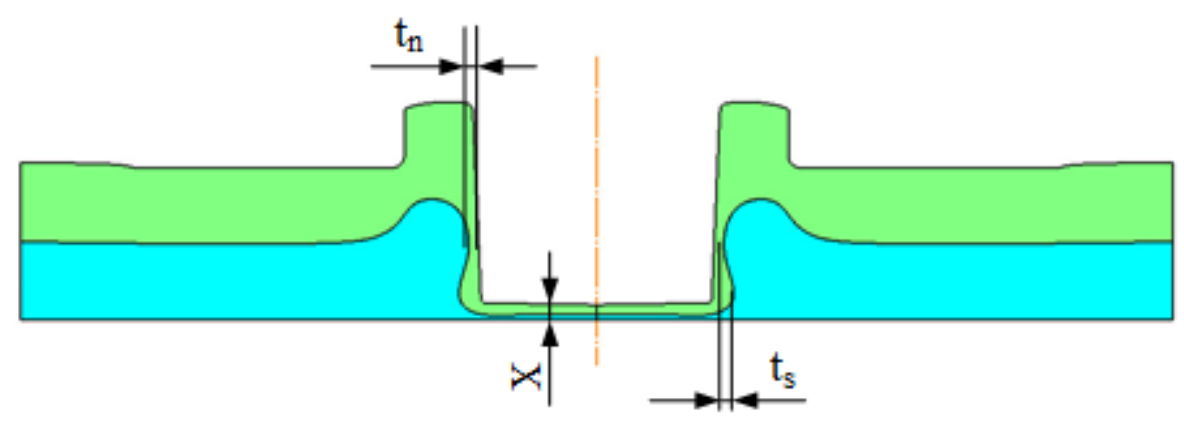

\section{Figure 2}

Main geometric parameters of the flat-clinched joint 


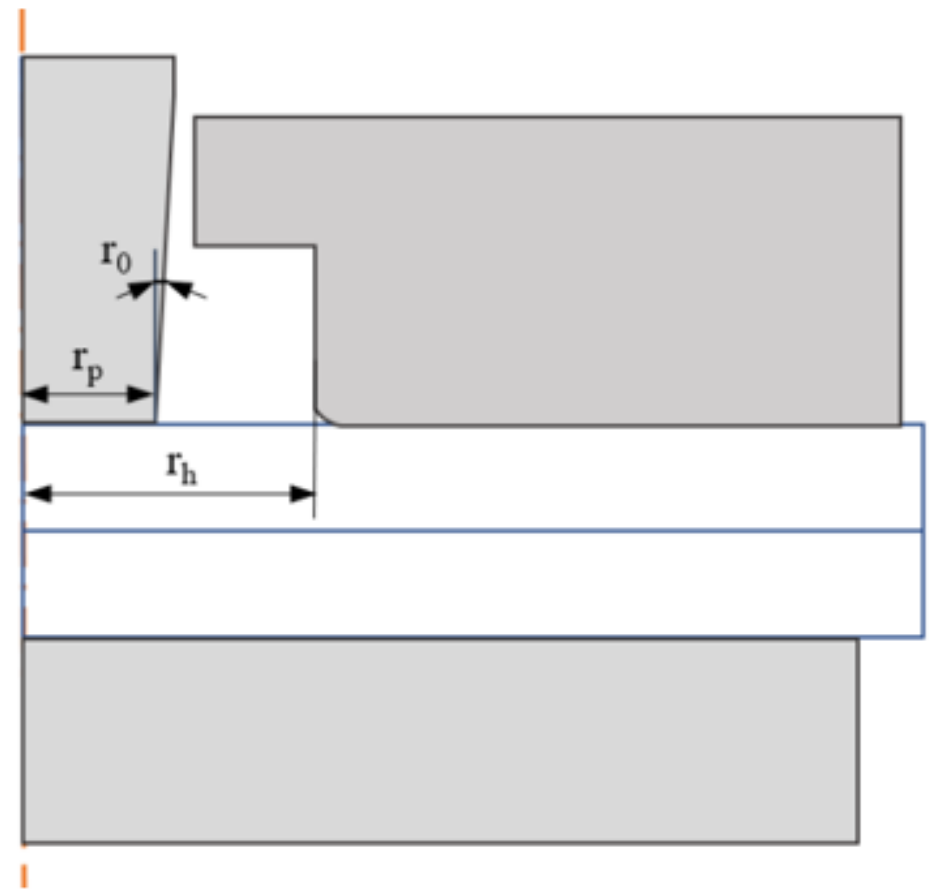

Figure 3

Main geometrical parameters of the tools
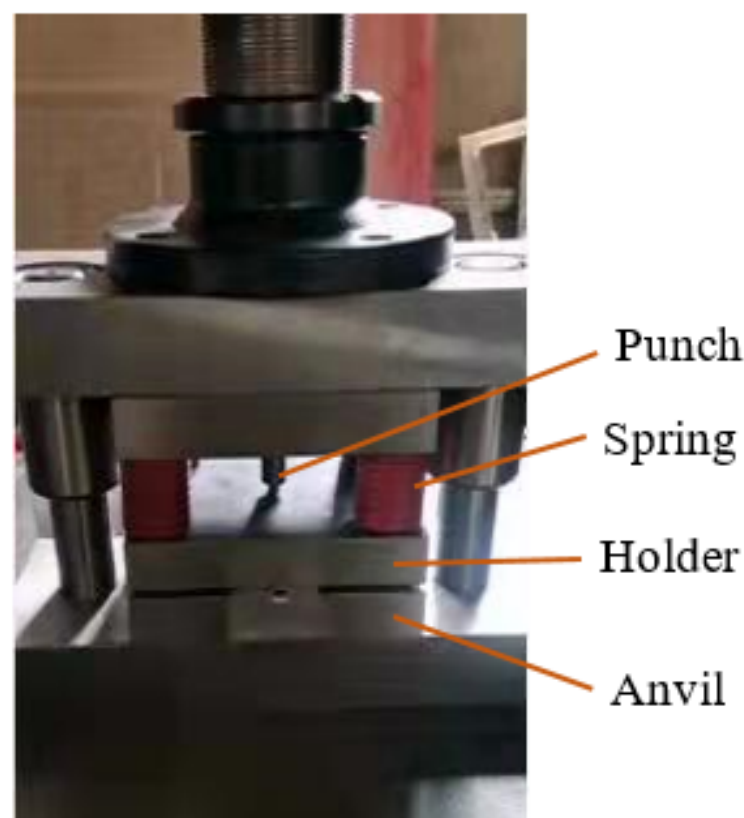

Figure 4

Experimental setup 


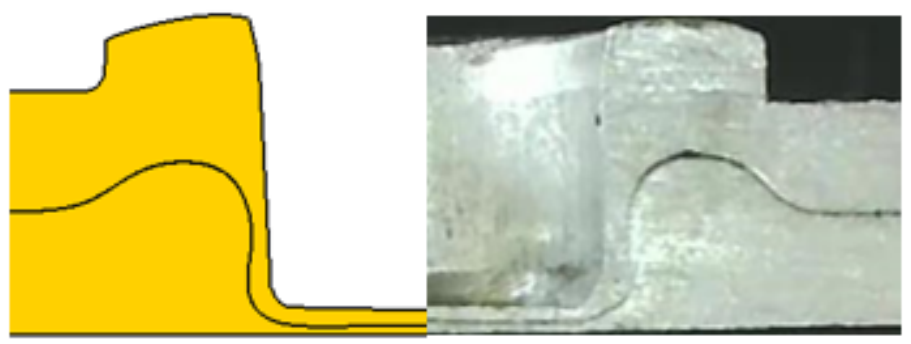

\section{Figure 5}

A comparison of numerical and experimental cross-sections of the flat-clinched joint
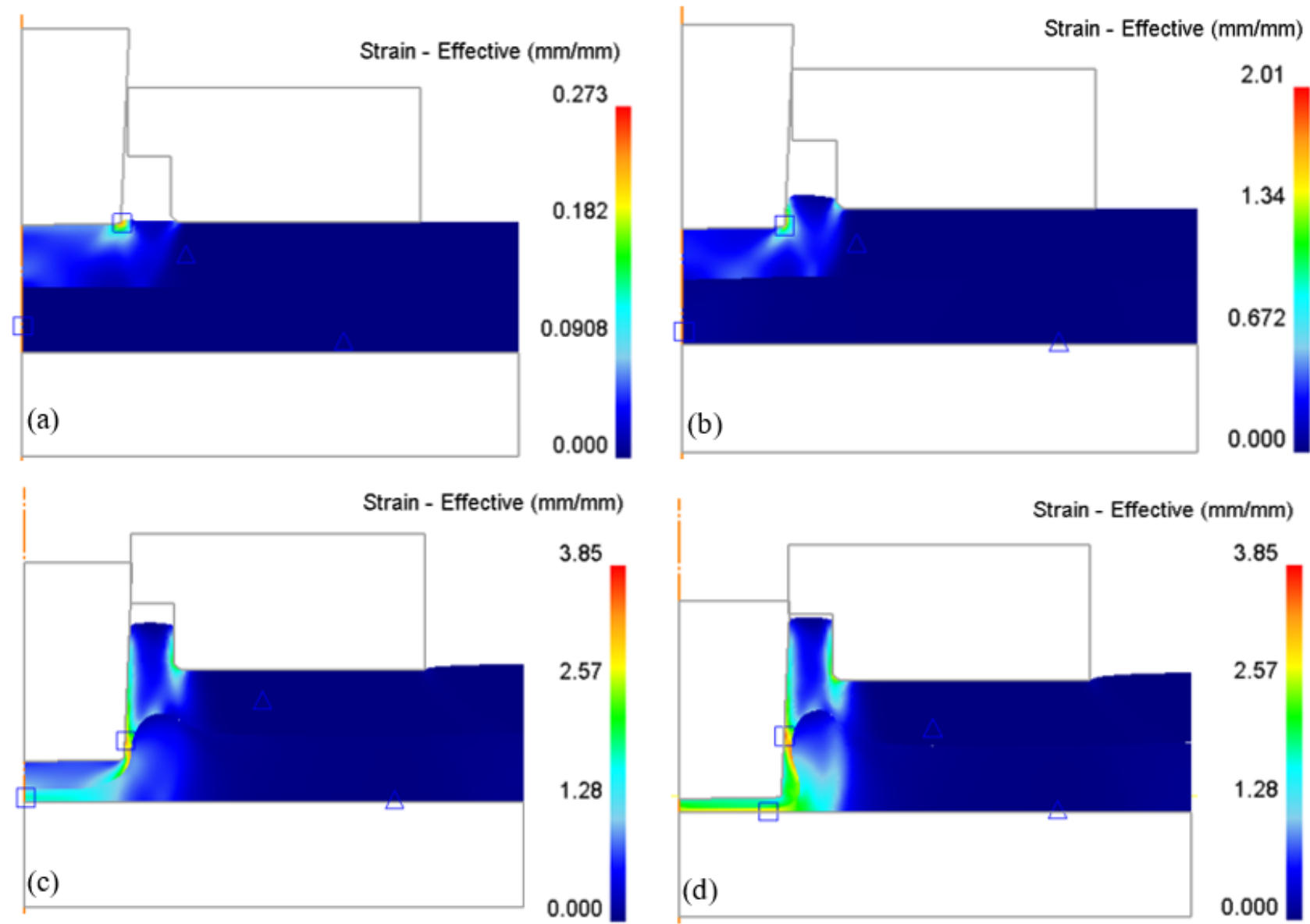

\section{Figure 6}

Material flow during the joining process: (a) local deforming, (b) drawing, (c) inverted extrusion, and (d) interlock forming. 


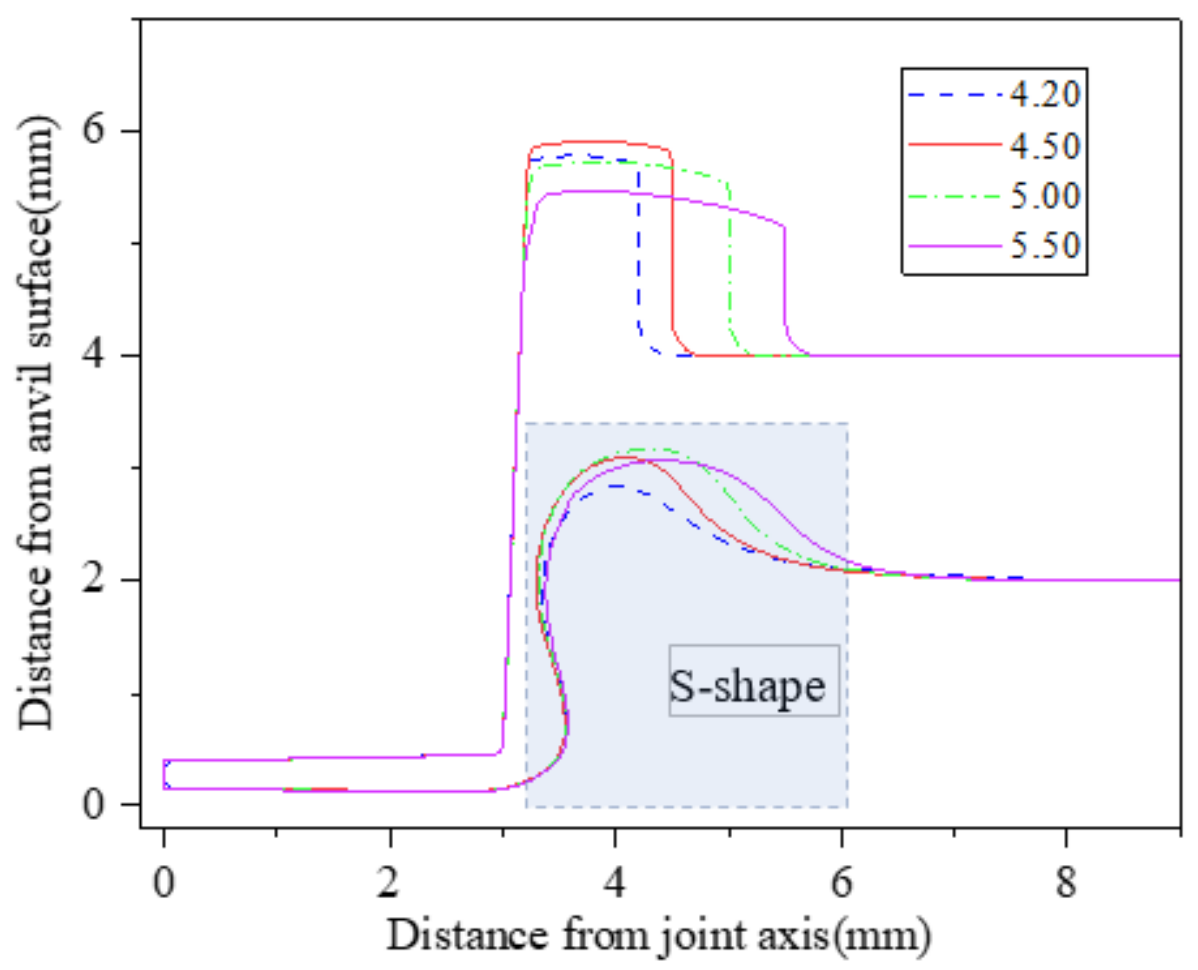

Figure 7

A comparison of flat-clinched joint shapes from different blank holder radii at $2.95 \mathrm{~mm}$ punch radius and $0.1 \mathrm{~mm}$ punch fillet radius

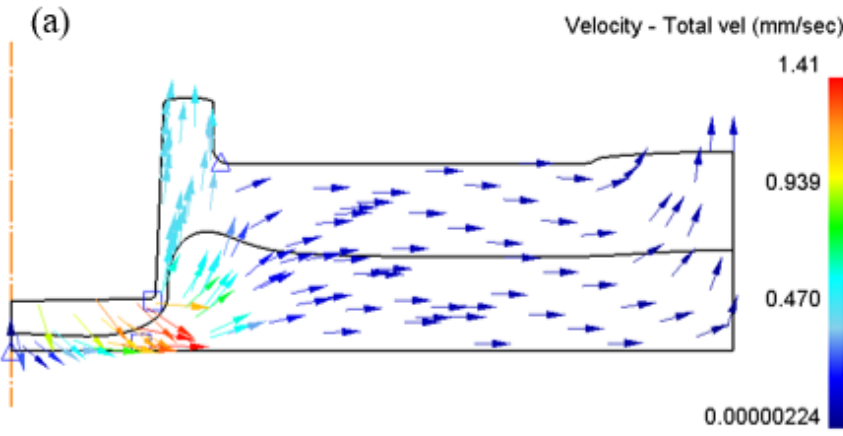

(c)

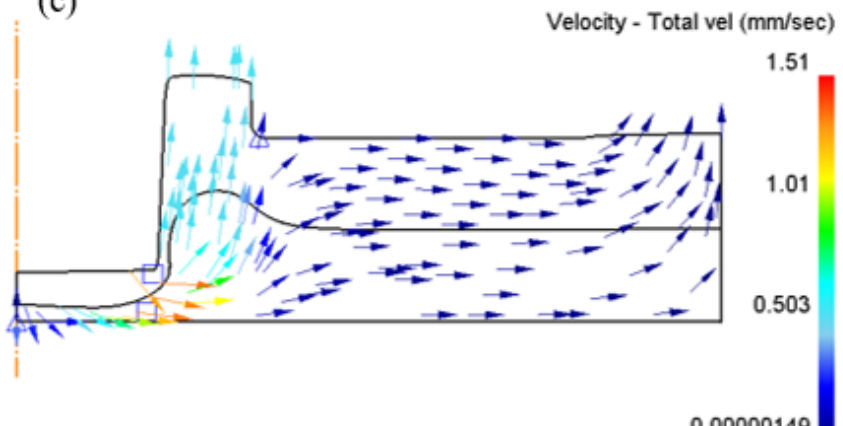

(b

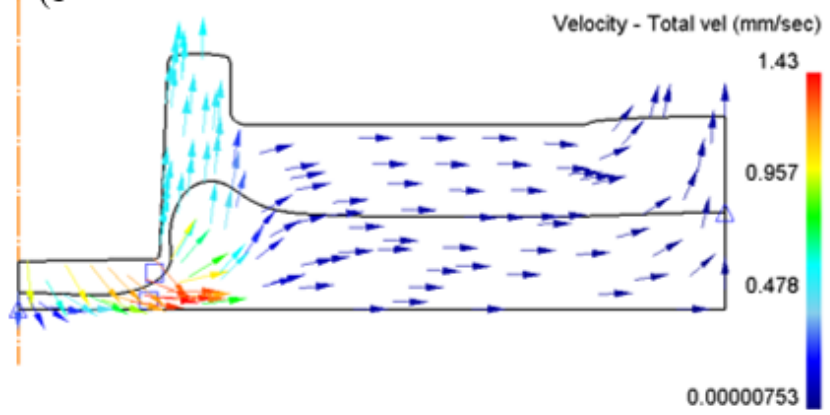

Velocity - Total vel $(\mathrm{mm} / \mathrm{sec})$

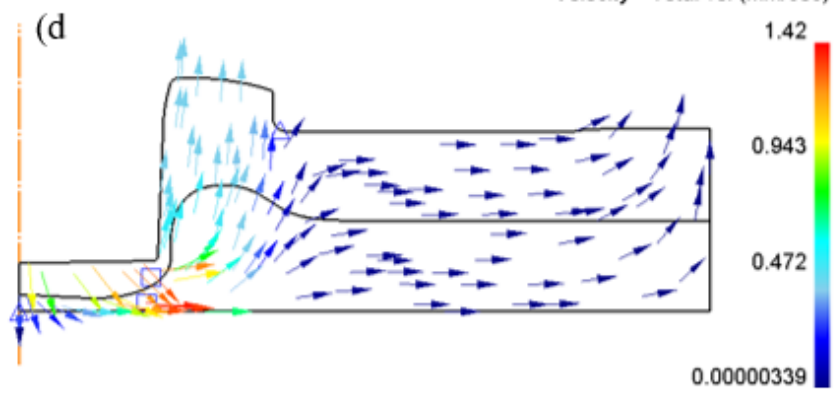

Figure 8 
Material flow velocity in the clinched region at $3.0 \mathrm{~mm}$ punch stroke with different blank holder radii (a) $4.2 \mathrm{~mm},(\mathrm{~b}) 4.5 \mathrm{~mm},(\mathrm{c}) 5.0 \mathrm{~mm},(\mathrm{~d}) 5.5 \mathrm{~mm}$

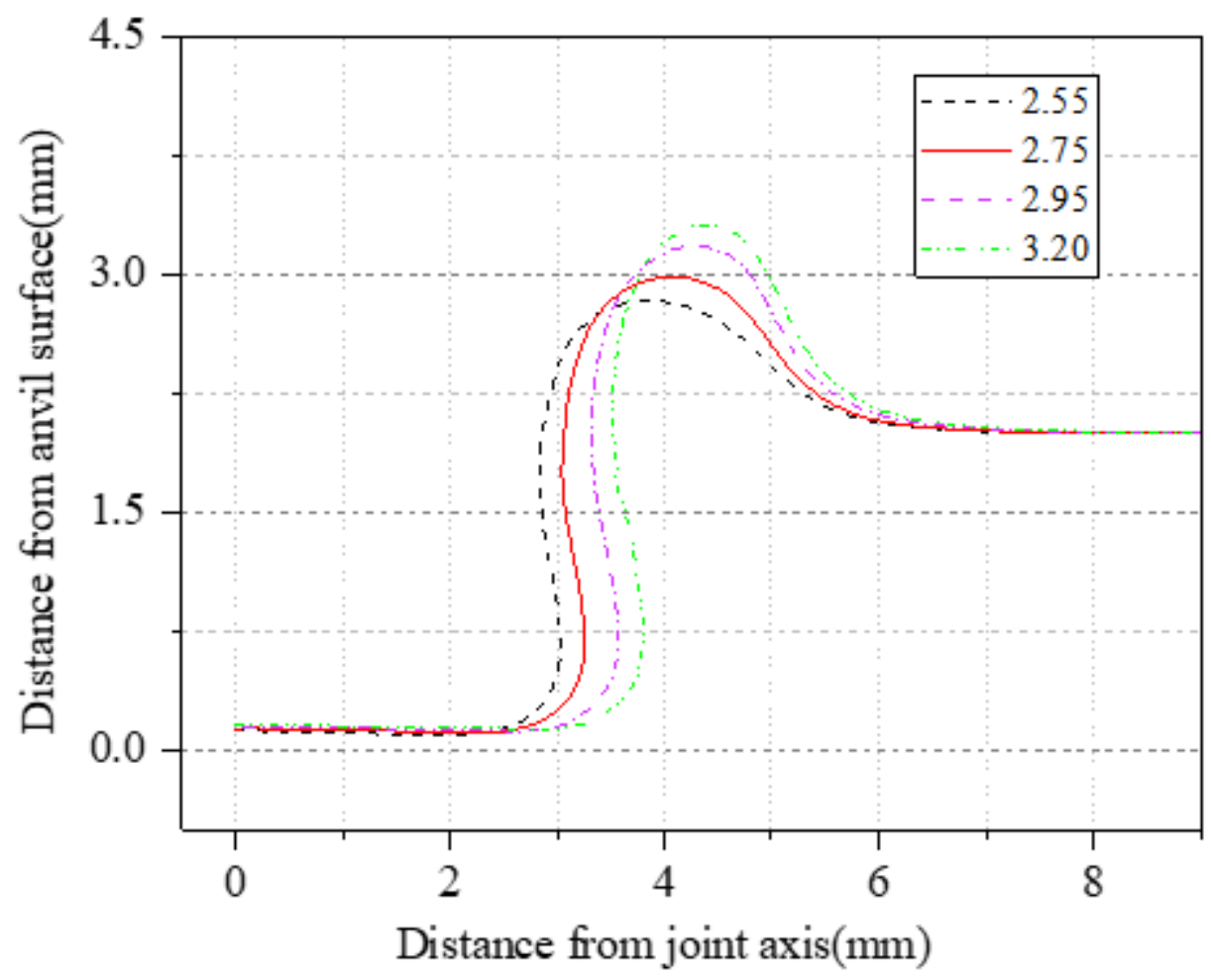

Figure 9

A comparison of interlock shapes from different punch radii

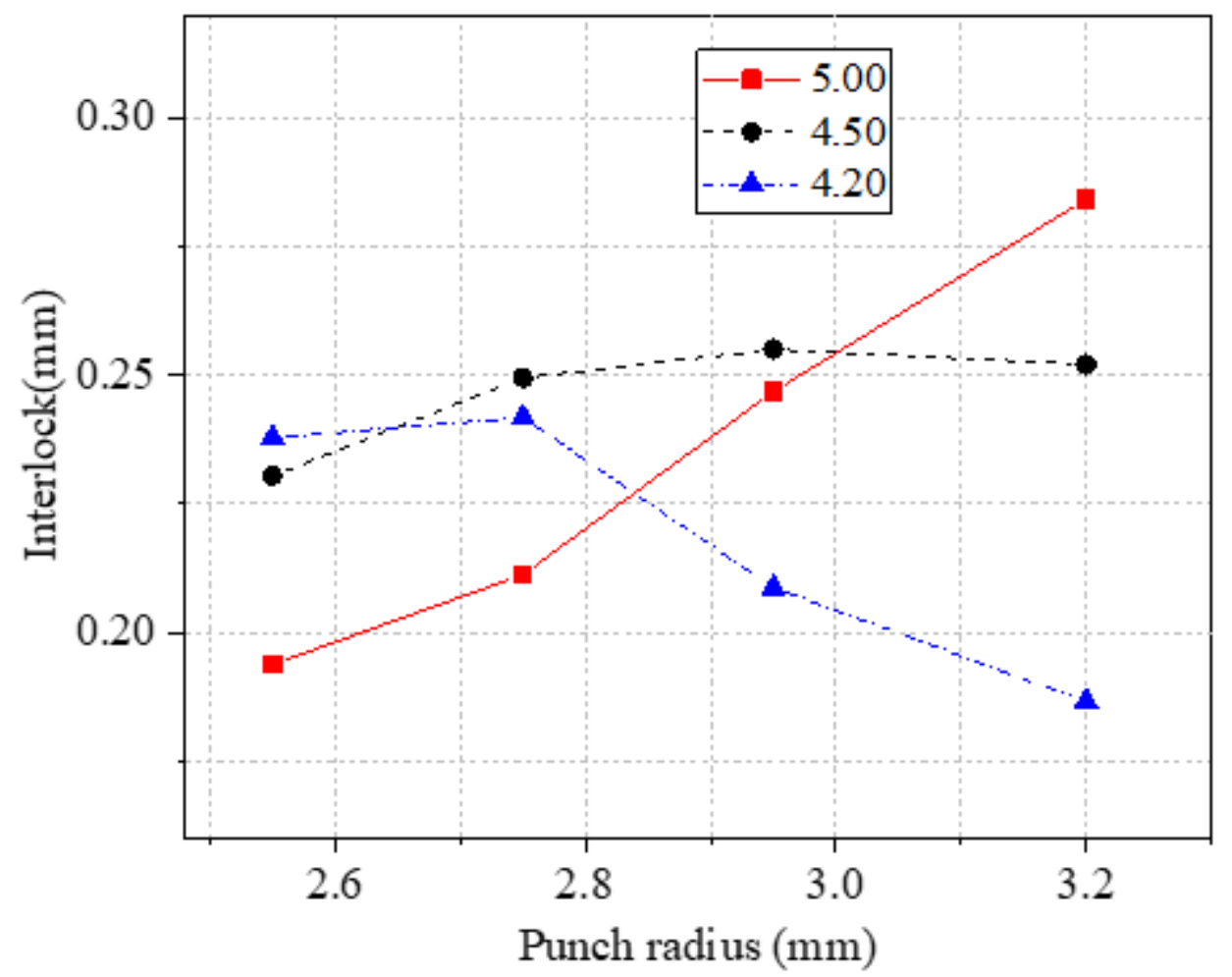


Figure 10

Effect of punch radius on the interlock at different blank holder radii
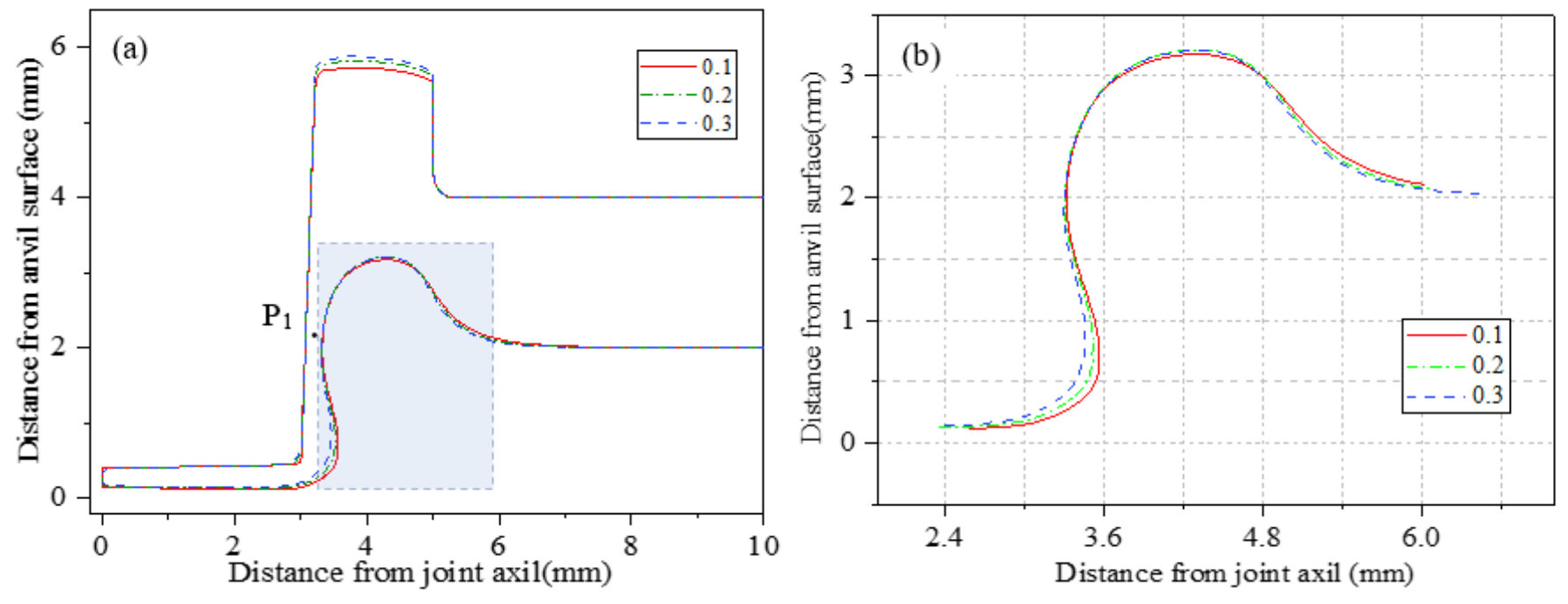

Figure 11

Effect of different punch fillet radii on the final shape of the flat-clinched joints (a)overall view of the joints, and (b) enlarge view of the S-shapes

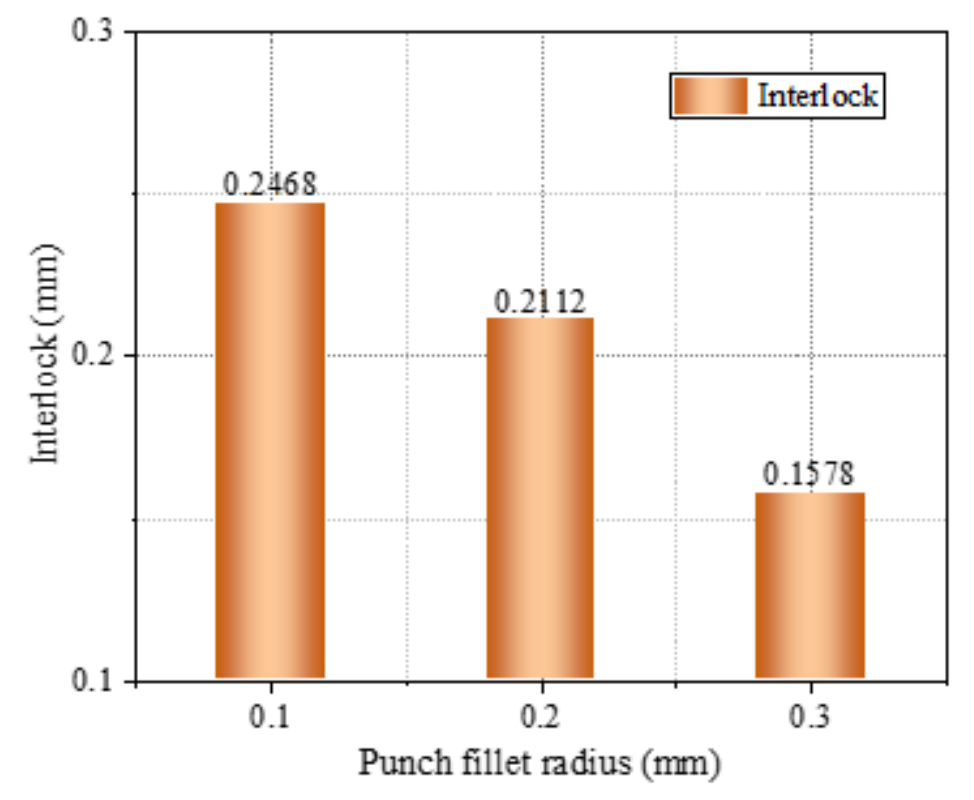

\section{Figure 12}

Interlocks of the flat-clinched joint at different punch fillet radii 


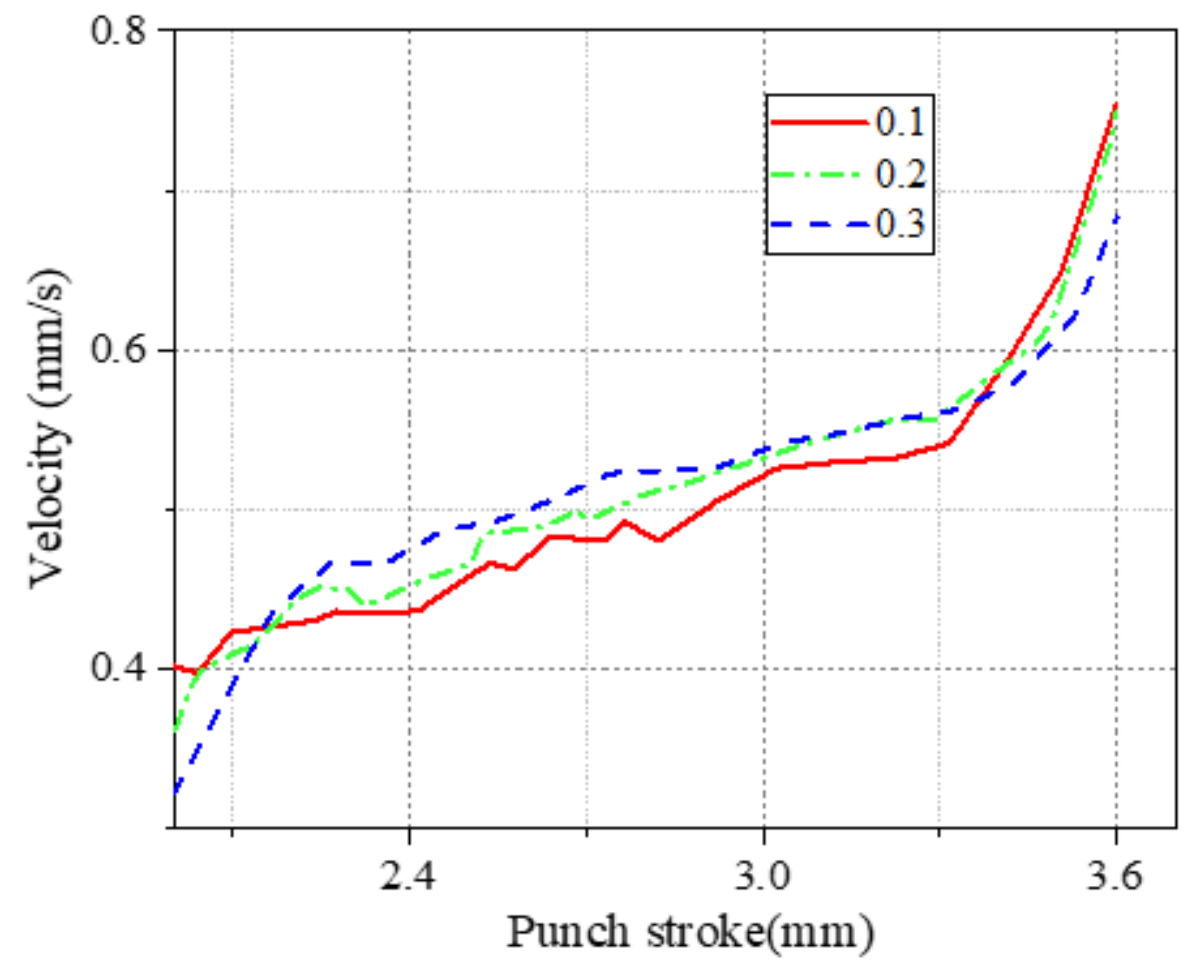

Figure 13

Material flow velocity in the axis direction at the fixed point P1 by point tracking
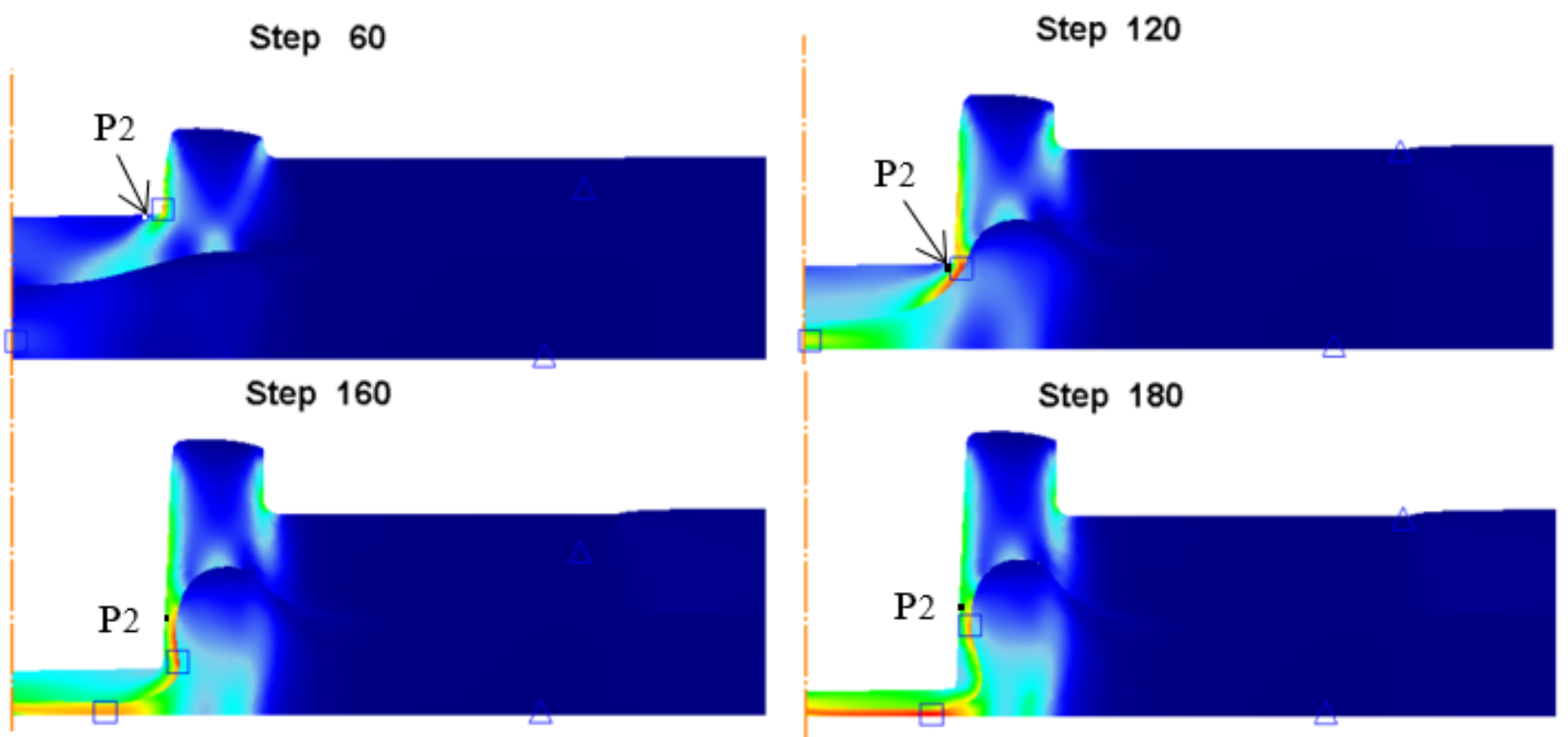

Figure 14 
Point tracking of the moving point $\mathrm{P} 2$ at punch fillet radius $0.1 \mathrm{~mm}$

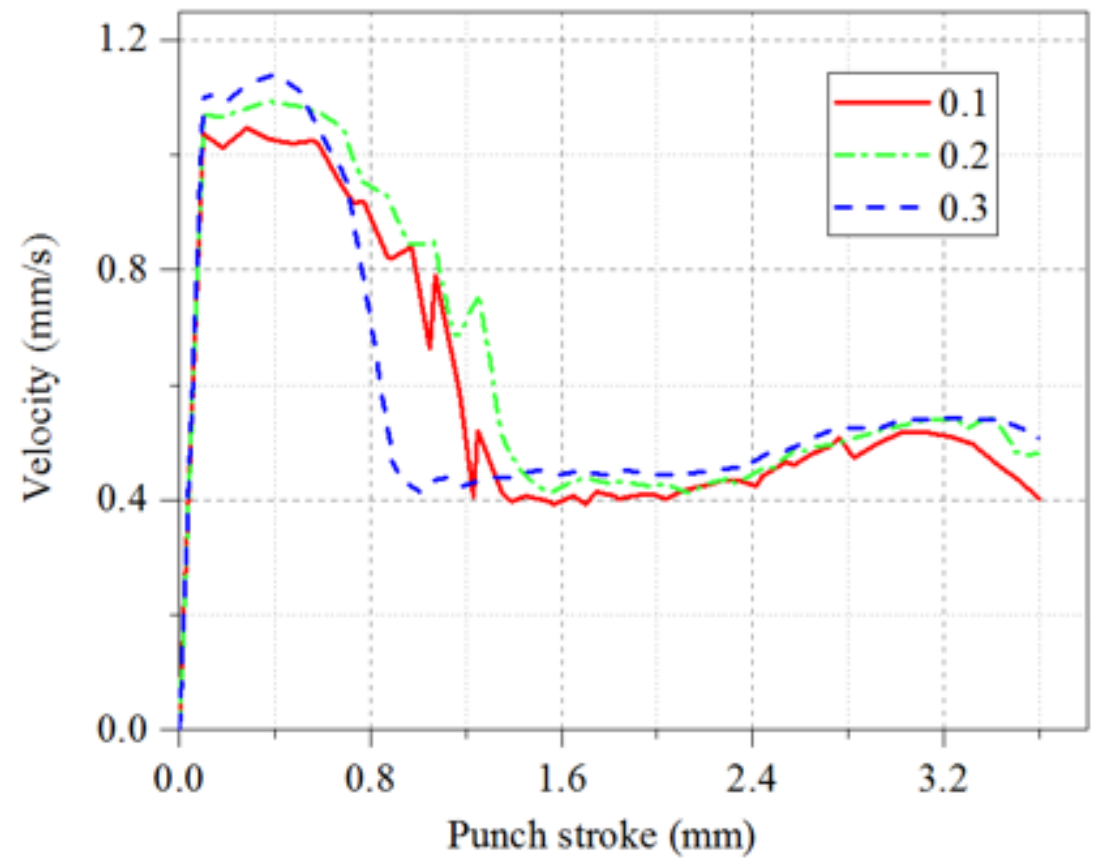

Figure 15

Velocity of the moving point P2 by point tracking 

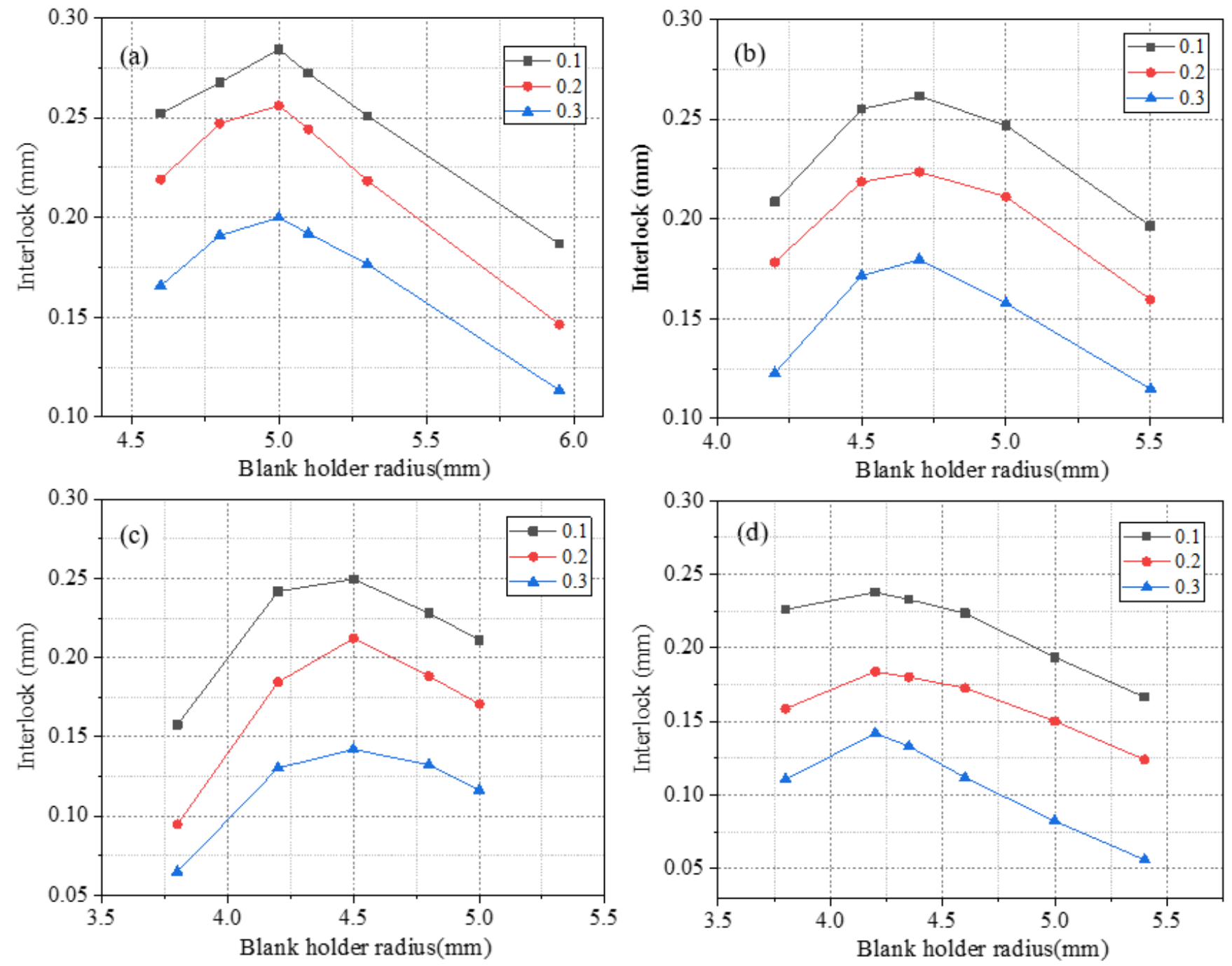

Figure 16

Effect of blank holder radius, punch fillet radius on the interlock at different punch radii (a) $3.20 \mathrm{~mm}$, (b) $2.95 \mathrm{~mm},(\mathrm{c}) 2.75 \mathrm{~mm}$, and(d) $2.55 \mathrm{~mm}$ 


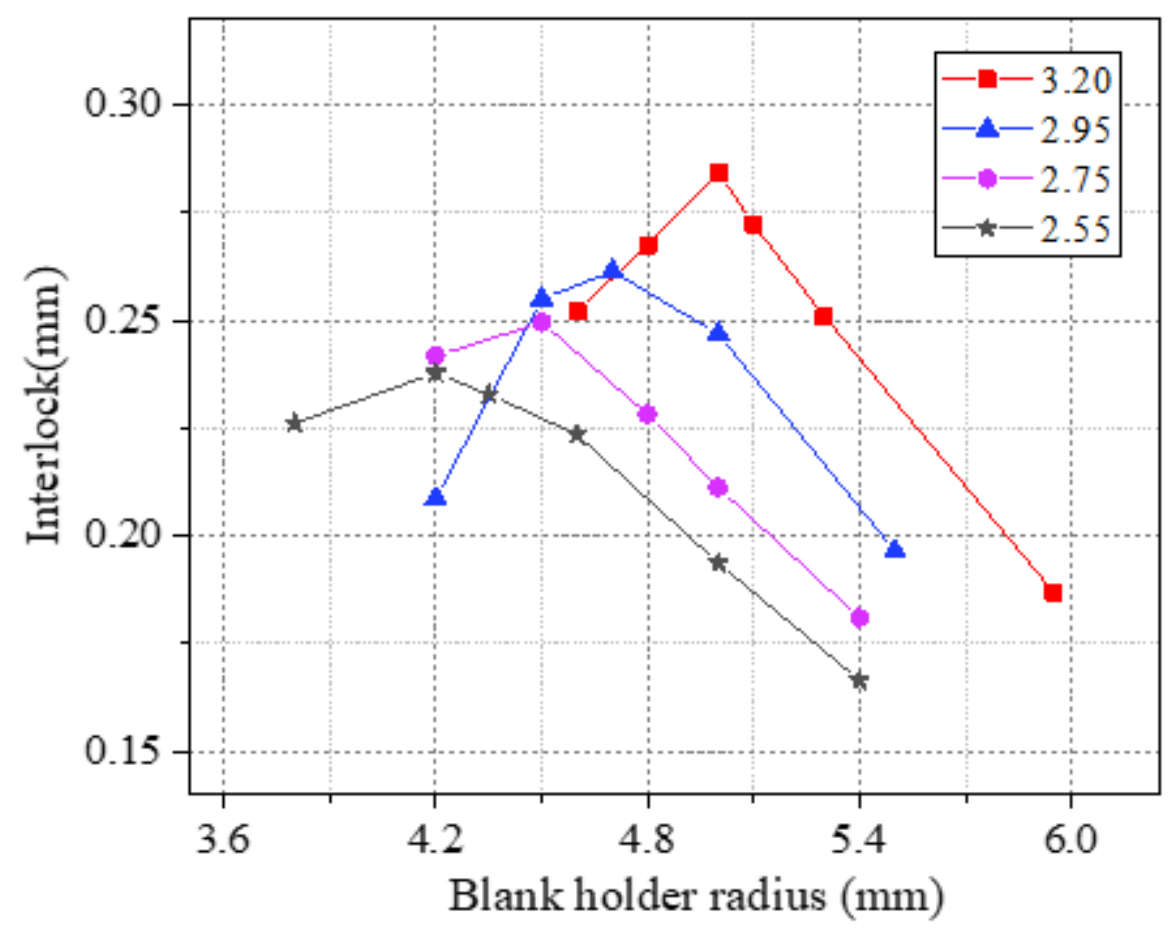

Figure 17

Effect of blank holder radius on the interlock at different punch radii

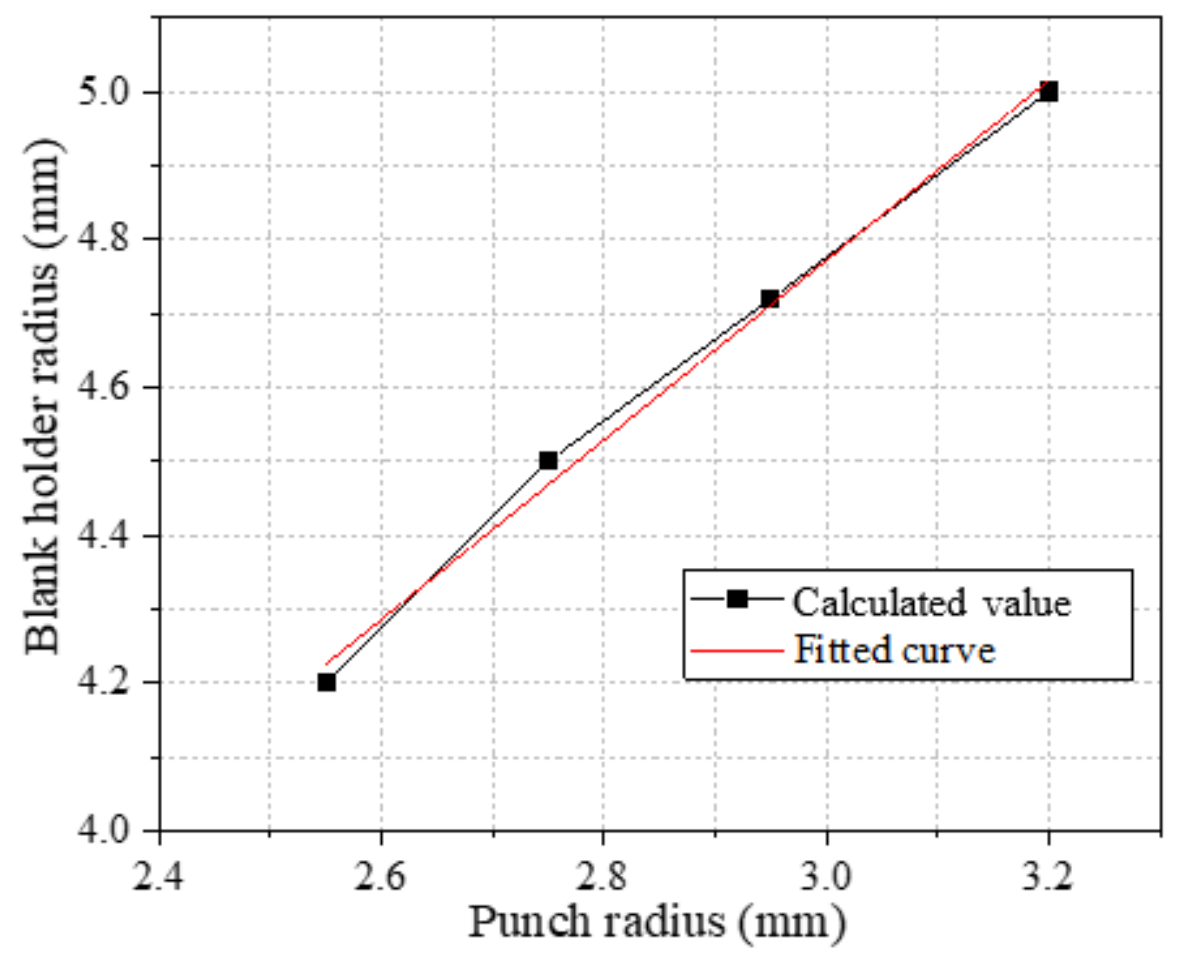

Figure 18

Relationship between punch radius and blank holder radius for the best interlock 